\title{
The Ontario Integrated Supervised Injection Services Cohort Study of People Who Inject Drugs in Toronto, Canada (OiSIS-Toronto): Cohort Profile
}

\author{
Ayden I. Scheim • Ruby Sniderman • Ri Wang • Zachary Bouck • Elizabeth McLean • \\ Kate Mason • Geoff Bardwell • Sanjana Mitra • Zoë R. Greenwald • Kednapa Thavorn • \\ Gary Garber • Stefan D. Baral • Sean B. Rourke • Dan Werb $(\mathbb{D}$
}

Accepted: 6 May 2021/ Published online: 28 June 2021

(C) The Author(s) 2021

\begin{abstract}
The Ontario Integrated Supervised Injection Services cohort in Toronto, Canada (OiSIS-Toronto) is an open prospective cohort of people who inject drugs (PWID). OiSIS-Toronto was established to evaluate the impacts of supervised consumption services (SCS) integrated within three community health agencies on health status and service use. The cohort includes PWID who do and do not use SCS, recruited via self-referral, snowball sampling, and community/street outreach. From 5 November 2018 to 19 March 2020, we enrolled 701 eligible PWID aged 18+ who lived in Toronto. Participants complete interviewer-administered questionnaires at baseline and semi-annually thereafter and are asked to consent to linkages with provincial healthcare administrative databases $(90.2 \%$ consented; of whom $82.4 \%$
\end{abstract}

A. I. Scheim

Department of Epidemiology and Biostatistics, Dornsife School of Public Health, Drexel University, Philadelphia, PA, USA

\author{
A. I. Scheim · R. Sniderman · Z. Bouck - E. McLean • \\ Z. R. Greenwald · D. Werb $(\bowtie)$ \\ Centre on Drug Policy Evaluation, Li Ka Shing Knowledge \\ Institute, St. Michael's Hospital, 30 Bond Street, Toronto, ON \\ M5B 1X1, Canada \\ e-mail: dwerb@health.ucsd.edu
}

\section{A. I. Scheim}

Department of Epidemiology and Biostatistics, Schulich School of Medicine and Dentistry, Western University, London, ON, Canada were successfully linked) and SCS client databases. At baseline, $86.5 \%$ of participants $(64.0 \%$ cisgender men, median $([\mathrm{IQR}]$ age $=39$ [33-49]) had used SCS in the previous 6 months, of whom most (69.7\%) used SCS for $<75 \%$ of their injections. A majority $(56.8 \%)$ injected daily, and approximately half (48.0\%) reported fentanyl as their most frequently injected drug. As of 23 April 2021, $291(41.5 \%)$ participants had returned for follow-up. Administrative and self-report data are being used to (1) evaluate the impact of integrated SCS on healthcare use, uptake of community health agency services, and health outcomes; (2) identify barriers and facilitators to SCS use; and (3) identify potential enhancements to SCS delivery. Nested sub-studies include evaluation of "safer opioid supply" programs and impacts of COVID-19.

\author{
R. Wang · S. B. Rourke \\ MAP Centre for Urban Health Solutions, Li Ka Shing Knowledge \\ Institute, St. Michael's Hospital, Toronto, ON, Canada
}

Z. Bouck · Z. R. Greenwald

Dalla Lana School of Public Health, University of Toronto, Toronto, ON, Canada

K. Mason

South Riverdale Community Health Centre, Toronto, ON, Canada

G. Bardwell
Department of Medicine, University of British Columbia, St.
Paul's Hospital, 608-1081 Burrard Street, Vancouver, BC, Canada 
Keywords Cohort studies · People who inject drugs · Supervised injection $\cdot$ Health services research . Addictions

\section{Background}

It is estimated that $2016,0.70 \%$ of Canadians aged 15 to 64 years used injection drugs, up from $0.55 \%$ in 2011 [1]. In the context of unregulated drug markets and unsafe

G. Bardwell · S. Mitra

British Columbia Centre on Substance Use, 400-1045 Howe

Street, Vancouver, BC, Canada

\section{S. Mitra}

Interdisciplinary Studies Graduate Program, University of British Columbia, 2357 Main Mall, Vancouver, BC 270, V6T 1Z4, Canada

K. Thavorn

Ottawa Hospital Research Institute, The Ottawa Hospital, Ottawa, ON, Canada

K. Thavorn

School of Epidemiology and Public Health, University of Ottawa, Ottawa, ON, Canada

G. Garber

Department of Medicine, University of Ottawa, Ottawa Hospital Research Institute, 501 Smyth Box, Ottawa, ON, Canada

S. D. Baral

Department of Epidemiology, John Hopkins University School of Public Health, Baltimore, MD, USA

S. B. Rourke

Department of Psychiatry, University of Toronto, Toronto, ON, Canada

D. Werb

Institute of Health Policy, Management and Evaluation, University of Toronto, Toronto, ON, Canada

D. Werb

Division of Infectious Diseases and Global Public Health, University of California San Diego School of Medicine, La Jolla, CA, USA injecting practices, injection drug use is associated with overdose, HIV and Hepatitis C transmission, soft tissue infections, and endocarditis [1]. Overdose rates in Canada have increased due to penetration of fentanyl and its analogues in the illicit drug market; $82 \%$ of accidental opioid overdose deaths in 2020 involved fentanyl [2]. In Ontario, Canada's most populous province, there were 15.3 opioid-related overdose deaths per 100,000 people between January and September 2020, among the highest provincial rates in the country [2]. Toronto, Ontario's capital, accounts for $20 \%$ of the province's overdose deaths [3]. In response to an already-worsening opioid overdose crisis, supervised consumption services (SCS) in Toronto began to open in 2017, along with scale-up of other harm reduction interventions (e.g., naloxone distribution, opioid agonist treatment [OAT]).

SCS are health services where people who inject drugs (PWID) consume pre-obtained drugs under the supervision of health professionals and/or trained peers, and can access clean injection/inhalation equipment, basic healthcare such as wound care, and referrals to other services [4]. Many SCS also permit swallowing, snorting, and (less commonly in Canada) smoking of drugs. Staff are trained to respond to overdoses, and there are no recorded cases of overdose death within an SCS [5, 6]. There are approximately 120 SCS worldwide with operating models including stand-alone storefronts, injecting rooms integrated within existing community health services, in-hospital SCS, and mobile vans [5, 6].

Individual-level and ecological studies of SCS effectiveness have indicated that SCS are associated with reduced overdose mortality, reduced syringe sharing and infection disease risk, and increased uptake of detoxification and addiction treatment services [6-9]. SCS implementation has also been associated with decreases in public injecting and publicly discarded syringes $[6,10$, 11]. In Vancouver, frequent SCS use was associated with reduced all-cause mortality among PWID [12]. There is no scientific evidence that SCS are associated with increases in injection drug use initiation or crime [6, 13, 14].

Existing quantitative evaluations of SCS have necessarily been observational or quasi-experimental, given the lack of equipoise to justify a randomized trial $[14,15]$. However, potentially addressable limitations of the extant evidence have been identified, including a lack of SCSunexposed comparison groups in most studies, assumptions about whether behavior change within SCS extends to off-site drug use, and limitations of self-report [15]. In addition, approximately $80 \%$ of existing SCS research 
focuses on two sites in Vancouver, Canada, and Sydney, Australia $[6,13,14]$. These sites have similar high-volume, stand-alone models and most of the studies were conducted prior to the current overdose crisis. Vancouver differs from other Canadian cities in multiple respects relevant to SCS implementation, including a dense concentration of injection drug use in one neighborhood and a temperate climate. Therefore, there is a critical need for studies that examine the effectiveness of SCS in a wider range of geographic and cultural settings, and in the context of heightened overdose risk. Furthermore, there have been calls for research on implementation specifics of SCS (e.g., design, [co]-location, service integration, rules, hours of operation) to understand how various features of SCS impact their effectiveness [14, 16].

To address these critical gaps, the Ontario Integrated Supervised Injection Services cohort study in Toronto (OiSIS-Toronto) was established in November 2018 to evaluate the first three sanctioned SCS in the city. Each is integrated within an existing community health agency (CHA), including two comprehensive community health centers and one harm reduction program. SCS were first implemented in Toronto in the summer of 2017 with an unsanctioned site situated in a downtown park, [17] and the first sanctioned SCS opened in August 2017. Both SCS and overdose prevention sites are herein referred to collectively as SCS, a term we use to reflect that the sites permit consumption by multiple routes. As of December 2020, there were nine SCS operating in Toronto. In response to the worsening overdose crisis, a range of harm reduction innovations emerged beyond SCS, notably a street drug-checking program [18] and "safer opioid supply (SOS)" programs. SOS are harm reduction programs aiming to reduce overdose risk by prescribing pharmaceutical opioids in place of unregulated street opioids [19]. These are interventions with high plausibility but limited empirical evidence bases; therefore, the cohort additionally provides an evaluative framework to test these emerging harm reduction interventions. Herein, we describe the cohort protocol and participant characteristics.

\section{Methods}

Study Goals and Design

OiSIS-Toronto is an open prospective cohort of PWID who do and do not use SCS. The primary goals of the
OiSIS cohort are to (1) evaluate the impact of various integrated SCS models on client uptake of CHA programming, health service use, and health outcomes; (2) to identify barriers to SCS use; and (3) to identify potential operational and regulatory enhancements to SCS. The cohort draws on three data sources: (1) semi-annual interviewer-administered study questionnaires; (2) linkages to administrative databases at ICES, Ontario's repository for vital statistics and health administrative data; and (3) linkages to visit-level data from electronic SCS databases at the three CHAs. Consent is sought separately for data linkages and participants may enroll in the cohort without consenting to linkage.

Baseline data collection began on 5 November 2018; as the cohort is open, herein we report on participants enrolled by 19 March 2020, prior to the temporary suspension of new enrolments due to COVID-19 restrictions in Toronto. At present, we plan to follow participants up to 2.5 years from baseline for a total of six study visits occurring at semi-annual intervals. The study was approved by the Research Ethics Boards at Unity Health Toronto, the University of Toronto, and Toronto Public Health.

\section{Setting}

Toronto is the largest city in Canada (2017 population $=$ 2.93 million) and among the most ethno-racially diverse in the world. Beginning in 2016, overdose rates in Toronto rose precipitously as the street opioid supply became increasingly potent, as heroin was supplemented with, and ultimately largely replaced by, fentanyl [4, 20]. The first three SCS in Toronto, which OiSISToronto was established to evaluate, opened between August 2017 and March 2018. Characteristics of these SCS are described in Table 1.

\section{Participants}

At baseline, eligible participants had to be 18 years of age or older, report injecting illicit drugs within the previous 6 months, able to speak and understand English, and residing in Toronto. Recruitment materials specified that participants did not need to use SCS to enroll. Clients of the study SCS were primarily recruited on-site at the CHAs. Recruitment of participants who do not use SCS was designed with the aim of composing a comparator group experiencing similar structural vulnerabilities as those who use 
Table 1 SCS participating in the OiSIS-Toronto cohort study

\begin{tabular}{|c|c|c|c|}
\hline Characteristic & $\begin{array}{l}\text { Queen West Community Health } \\
\text { Centre }\end{array}$ & $\begin{array}{l}\text { South Riverdale Community } \\
\text { Health Centre }\end{array}$ & The Works \\
\hline Service model & $\begin{array}{l}\text { SCS integrated in health center } \\
\text { providing medical, mental } \\
\text { health, and social care to } \\
\text { vulnerable populations }\end{array}$ & $\begin{array}{l}\text { SCS integrated in health center } \\
\text { providing medical, mental } \\
\text { health, and social care to } \\
\text { vulnerable populations }\end{array}$ & $\begin{array}{l}\text { SCS integrated in harm reduction } \\
\text { program serving persons who use } \\
\text { drugs, including on-site nursing care } \\
\text { and OAT clinic }\end{array}$ \\
\hline Consumption modes & $\begin{array}{l}\text { Injection; intranasal; oral (>99\% } \\
\text { injection) }\end{array}$ & $\begin{array}{l}\text { Injection; intranasal; oral (>95\% } \\
\text { injection) }\end{array}$ & Injection \\
\hline $\begin{array}{l}\text { Peer-assisted injecting } \\
\text { allowed? (as of } \\
\text { March 2020) }\end{array}$ & Yes & Yes & No \\
\hline $\begin{array}{l}\text { Street drug checking } \\
\text { service available? }\end{array}$ & Yes & Yes & Yes \\
\hline $\begin{array}{l}\text { Booths and hours of } \\
\text { operation }\end{array}$ & $\begin{array}{l}\text { Four booths; } 45.5 \text { h/week over } 5 \\
\text { days }\end{array}$ & $\begin{array}{l}\text { Four booths; } 42.0 \mathrm{~h} / \text { week over } 5 \\
\text { days }\end{array}$ & Six booths, $78.0 \mathrm{~h} /$ week over 7 days \\
\hline $\begin{array}{l}\text { Average visits per } \\
\text { month (until } \\
\text { March 2020) }\end{array}$ & 522 & 549 & 3200 \\
\hline
\end{tabular}

SCS, and involved a combination of active outreach by study staff at CHAs; non-incentivized peer recruitment; and passive recruitment (posters, recruitment cards) at health and social service organizations, on the street, and in needle and syringe packages distributed by CHAs. To avoid eligibility restrictions that might lead to misrepresentation, we also enrolled individuals who use non-study SCS, using the same methods as for non-SCS users. These participants are grouped with other SCS users for analyses of overall SCS outcomes and disaggregated where particular SCS models are being compared. Study interviews are completed at one of the three participating CHAs, or at the research team offices if an alternative site is requested by a participant. At each visit, participants complete an intervieweradministered computer-based questionnaire and receive a CDN $\$ 30$ honorarium. All participants provided written informed consent for cohort participation and (separately) data linkages.

\section{Retention and Follow-Up}

OiSIS-Toronto employs a number of retention strategies commonly used in PWID cohorts [21, 22]. Multiple forms of contact information were collected for each participant, including identifying two persons who know but do not live with the participant and for social service organization staff with whom they regularly interacted. Drop-in hours are advertised during which participants can sign up for a same-day interview. Participants can receive honoraria for checking in with study staff between interview visits (CDN $\$ 5$ at the beginning of the study, later increased to $\$ 10$ ). We also use reminder cards, posters, and a toll-free number so that participants may phone the study office long-distance or from jail.

\section{Data Sources}

Variables to be derived from all data sources are summarized in Table 2.

\section{OiSIS-Toronto Questionnaire}

The questionnaire includes self-reported data on demographic characteristics and socio-structural exposures, drug use behaviors, use of SCS, overdose experiences and other health conditions, use of drug checking services, and substance use disorder treatment.

\section{Administrative Data}

Cohort participants are asked to consent to a having their study questionnaire data linked with administrative data at ICES, which broadly captures demographic information, vital statistics, and publicly funded healthcare encounters in Ontario. Consenting participants provide their Ontario Health Insurance Plan (OHIP) number and/or one or more of their name, date of birth, and postal code. This information is then used to link 
Table 2 Variables and data sources available for OiSIS-Toronto participants at baseline

\begin{tabular}{|c|c|c|}
\hline Content area & Key variables & Source \\
\hline Demographics and socio-structural exposures & $\begin{array}{l}\text { Age, sex assigned at birth and gender identity, sexual orientation, } \\
\text { race/ethnicity, education, income and income sources, housing, } \\
\text { recent incarceration }\end{array}$ & Questionnaire \\
\hline Drug use behaviors & $\begin{array}{l}\text { Injection and non-injection drug use (drugs used, frequency), } \\
\text { fentanyl-related behaviors and attitudes, public injection, } \\
\text { syringe and equipment sharing, provision of injection initiation } \\
\text { assistance, alcohol use [AUDIT-C] [23] }\end{array}$ & Questionnaire \\
\hline SCS use & $\begin{array}{l}\text { SCS use, SCS-related behavior change, SCS satisfaction, SCS } \\
\text { services accessed, referrals accessed }\end{array}$ & Questionnaire \\
\hline Overdose and other health conditions & $\begin{array}{l}\text { Overdose history and response, HIV status and treatment, } \\
\text { Hepatitis C status and treatment, depression [PHQ-9], [24] } \\
\text { drug-use related stigma }\end{array}$ & Questionnaire \\
\hline Drug checking services (DCS) & Interest and actual use of various DCS technologies & Questionnaire \\
\hline Substance use disorder treatment & $\begin{array}{l}\text { Engagement in pharmacologic and non-pharmacologic } \\
\text { treatment, satisfaction and preferences }\end{array}$ & Questionnaire \\
\hline Healthcare use & $\begin{array}{l}\text { Primary care, emergency department visits, and hospital } \\
\text { admissions (timing, frequency, diagnoses); mortality } \\
\text { and cause of death; dispensation of OAT }\end{array}$ & ICES \\
\hline SCS visit data & $\begin{array}{l}\text { Visit timing and frequency, drugs consumed, overdose } \\
\text { events and disposition, referrals }\end{array}$ & SCS visit database \\
\hline
\end{tabular}

consenting participants with ICES data holdings either via their OHIP number (deterministic linkage) or using probabilistic linkage methods. Questionnaire data will be linked with the following ICES databases: the Registered Persons Database (demographic and vital statistics for all OHIP-eligible residents); the OHIP claims database (billing covering $\sim 95 \%$ of physicians in Ontario); the Discharge Abstract Database (hospital admissions and discharges); the National Ambulatory Care Reporting System (emergency department visits); the Client Agency Program Enrolment Registry (patient enrolment with individual primary care physicians); the Corporate Provider Database (physician and practice information); the Ontario Mental Health Reporting System (mental health admissions); CONTACT (eligibility summaries and yearly health services contact); the Ontario HIV Database (persons with HIV); and the Narcotic Monitoring System database (dispensations for controlled medications [including methadone and buprenorphine/naloxone], irrespective of payment method).

\section{SCS Visit Database}

Participating CHAs track SCS use in an electronic database; two of three sites use NEO 360, a computerized record-keeping system used by harm reduction programs across Ontario [25]. To track client-level visit data, clients are asked to create a unique identification code and to provide it at each visit but can opt-out of creating a code to access the service entirely anonymously. SCS use records are not linked to other CHA records, including electronic medical records. Participants who use the three study SCS are asked for permission to access their SCS visit history via their code.

\section{Nested Studies}

\section{Qualitative Studies of SCS Implementation Contexts}

In the summer of 2018, a qualitative study was conducted at two study SCS to understand barriers and benefits to accessing integrated SCS, including any contextual factors that affected uptake $[26,27]$. Individual semistructured interviews were completed with 24 participants and ethnographic observations were gathered. In October 2019, rapid ethnographic research was conducted in the neighborhood surrounding a third SCS in downtown Toronto to examine public drug use and "public order." This latter study included participant observation (e.g., police, security guards, people who 
use drugs, general public) and built environment observation, as well as informal conversations.

\section{Quantitative Sub-studies}

Since October 2020, OiSIS-Toronto participants who indicate they are enrolling in an SOS program have been invited to participate in a sub-study assessing clinical, health, and social outcomes associated with SOS. Additionally, we conducted a rapid survey to assess the impact of COVID-19 and related restrictions on people who use drugs in Canada, which was administered to 170 cohort participants between June 2020 and April 2021, using a combination of telephone and in-person interviewing, and which was also administered to cohorts of people who use drugs in Vancouver and Montreal.

\section{Community Engagement}

Representatives of the CHAs participating in the study are co-investigators on the project. Participating CHAs have pre-existing community advisory bodies comprised of people who use drugs, who are compensated for their time and expertise. The community advisory bodies are consulted on an ongoing basis on study recruitment and retention procedures, priority research topics, and approaches for disseminating findings to community members. People with lived experience of drug use are prioritized for research staff positions; importantly, this commitment has required advocacy and creativity within a hospital system in which formal educational credentials and criminal background checks are typically required for hiring. While all staff eventually went through those institutional processes, we provided them with close support, including financial assistance to obtain identification needed for the background checks.

\section{Data Analysis}

We calculated descriptive statistics to describe demographic, health status, and drug use characteristics of cohort participants, overall, and stratified by selfreported frequency of SCS use (use of SCS for none, few $[\leq 25 \%]$, some [26-74\%], or all or most $[\geq 75 \%]$ of their injections) and by retention status ( $\geq 1$ follow-up visit vs. lost to follow-up). We used Wilcoxon rank-sum tests and chi-square tests, for continuous and categorical variables respectively, to test for differences in characteristics. We also calculated frequencies of drug-related risks in the full sample.

\section{Results}

\section{Recruitment and Data Linkage}

As shown in Fig. 1, as of 19 March 2020, 761 baseline interviews were conducted and 60 interviews were removed from the study due to ineligibility or duplicate interviews. In total, 701 eligible participants were enrolled, including $520(74.2 \%)$ who used one of the SCS being evaluated, 89 (12.7\%) who used other SCS, and $92(13.1 \%)$ who did not use any SCS over the previous 6 months. As shown in Table 3, participating SCS clients were approximately evenly split between those who reported using SCS for all or most $(\geq 75 \% ; n=182)$, some $(26-74 \% ; n=215)$, or few $(\leq 25 \% ; n=204)$ of their injections.

Overall, 632 participants $(90.2 \%)$ consented to healthcare administrative data linkages and 521 $(82.4 \%)$ were successfully linked to ICES databases. In total, 280 study SCS clients $(53.8 \%)$ provided their client identification code for SCS database linkage, with substantial variation across sites (range $=28-66 \%$ ), likely due to variation in the extent to which sites actively promote creation and use of a consistent code.

\section{Socio-Demographic Characteristics}

Socio-demographic characteristics and drug use patterns are shown in Table 3, stratified by frequency of SCS use. At baseline, the median age of participants was 39 (interquartile range [IQR]: 33-49), and two-thirds were cisgender men $(64.3 \%, n=449)$. Approximately half of the participants were white $(53.6 \%)$ and one-third were Indigenous $(33.6 \%, n=235)$. The vast majority of participants were homeless or unstably housed $(90.7 \%$, $n=584 / 650$ ), and over one-third had recently been incarcerated $(38.0 \%, n=247 / 650)$. Most socio-demographic characteristics did not vary significantly by frequency of SCS use; however, compared to SCS clients, non-SCS users were older (median [IQR] age $=47.5$ [37.3-52.8]) and less likely to report some illicit or informal income sources. 


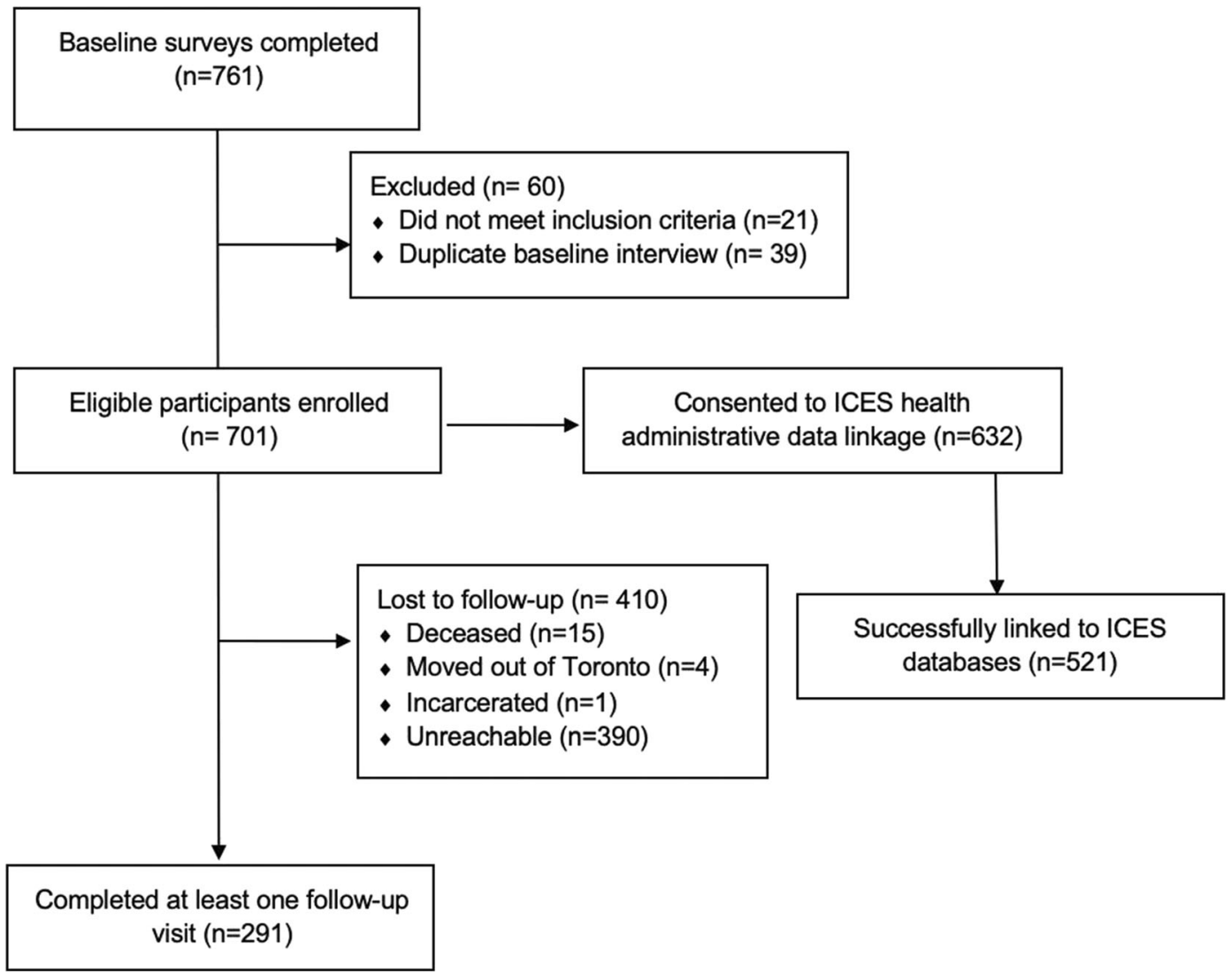

Fig. 1 Participant flow

HIV and Hepatitis C

Five percent of participants self-reported being HIVpositive $(n=35)$; self-reported HIV prevalence was lower among those who used SCS more frequently $(p<0.01)$. More than half $(52.3 \%, n=335)$ reported a lifetime diagnosis of Hepatitis C, of whom 57\% $(n=191)$ reported current, chronic infection.

Drug Use and Treatment Patterns

Approximately half of participants $(48.1 \%, n=333)$ reported fentanyl as their most frequently injected drug and SCS clients were more likely to do so ( $p$ $<0.01)$. Among non-SCS users, stimulant use was most common, with $60.8 \%(n=56)$ injecting either crystal methamphetamine or cocaine most often. Participants had been injecting for a median of 13 years; those who used SCS more frequently had shorter injecting histories $(p<0.01)$. Almost onethird $(32.5 \%, n=227)$ were receiving OAT at the time of their interview, including methadone (26.9\%, $n=188)$ and buprenorphine/naloxone $(4.9 \%, n=34)$. OAT use increased with SCS use frequency $(p=0.01)$.

\section{Drug-Related Risks}

Drug-related risks in the full sample are shown in Table 4. Over half of participants reported injecting daily $(56.8 \%$, $n=398$ ) over the previous 6 months and the majority $(81.4 \%, n=570)$ reported injecting in public. Most had injected alone $(88.1 \%, n=614)$ and $41.3 \%(n=289)$ had needed help to inject. Most participants did not share syringes (14.9\% borrowed and $17.1 \%$ lent; $n=104$ and 120) but more commonly reported sharing other injecting equipment such as cookers or filters $(37.2 \%, n=260)$. The majority of participants $(70.0 \%, n=489)$ had ever overdosed, and $38.6 \%(n=270)$ reported an overdose within the previous 6 months. In a published analysis, we found that this overdose risk was not independently associated with frequency of SCS use [28]. 
Table 3 Characteristics of OiSIS-Toronto participants by recent frequency of SCS use

\begin{tabular}{|c|c|c|c|c|c|c|}
\hline \multirow[t]{2}{*}{ Characteristic } & \multirow{2}{*}{$\begin{array}{l}\text { Total } \\
n=701 n(\%)\end{array}$} & \multicolumn{4}{|c|}{$\begin{array}{l}\text { Recent frequency of SCS use (proportion of all injections at } \\
\text { SCS)* }\end{array}$} & \multirow[t]{2}{*}{$\begin{array}{l}p \\
\text { value }\end{array}$} \\
\hline & & $\begin{array}{l}\text { All or most } \\
(\geq 75 \%) \\
n=182 n(\%)\end{array}$ & $\begin{array}{l}\text { Some } \\
(26-74 \%) \\
n=215 n(\%)\end{array}$ & $\begin{array}{l}\text { Few } \\
(\leq 25 \%) \\
n=204 n(\%)\end{array}$ & $\begin{array}{l}\text { None } \\
n=94 n(\%)\end{array}$ & \\
\hline Age (med, [IQR]) & $\begin{array}{l}39.0 \\
\quad(33.0-49.0)\end{array}$ & $\begin{array}{l}39.0 \\
\quad(33.0-48.0)\end{array}$ & $\begin{array}{l}36.0 \\
\quad(30.5-44.0)\end{array}$ & $\begin{array}{l}42.0 \\
\quad(34.0-51.0)\end{array}$ & $\begin{array}{l}47.5 \\
\quad(37.3-52.8)\end{array}$ & $<0.01$ \\
\hline Gender $(n=698)$ & & & & & & 0.15 \\
\hline Cisgender man & 449 (64.3) & $105(58.0)$ & $140(65.4)$ & $132(65.0)$ & $66(70.2)$ & \\
\hline Cisgender woman & $216(30.9)$ & $69(38.1)$ & $66(30.8)$ & $60(29.6)$ & $21(22.3)$ & \\
\hline Transgender or gender diverse & $33(4.7)$ & $7(3.9)$ & $8(3.7)$ & $11(5.4)$ & $7(7.4)$ & \\
\hline Sexual orientation $(n=695)$ & & & & & & 0.42 \\
\hline Sexual minority & $129(18.6)$ & $31(17.2)$ & $34(15.8)$ & $43(21.3)$ & $20(21.5)$ & \\
\hline Straight or heterosexual & $566(81.4)$ & $149(82.8)$ & $181(84.2)$ & 159 (78.7) & $73(78.5)$ & \\
\hline Ethnoracial group $(n=700)$ & & & & & & 0.91 \\
\hline Indigenous & $235(33.6)$ & $59(32.6)$ & $70(32.6)$ & $71(34.8)$ & $33(35.1)$ & \\
\hline Racialized, non-Indigenous & $90(12.9)$ & $20(11.0)$ & $27(12.6)$ & $29(14.2)$ & $14(14.9)$ & \\
\hline White, non-Indigenous & $375(53.6)$ & $102(56.4)$ & $118(54.9)$ & $104(51.0)$ & $47(50.0)$ & \\
\hline Homeless or unstably housed ${ }^{\dagger}(n=650)$ & $588(90.5)$ & $154(92.2)$ & $185(93.0)$ & $170(90.4)$ & $75(83.3)$ & 0.06 \\
\hline Recent incarceration ${ }^{\dagger}(n=650)$ & $247(38.0)$ & $54(32.3)$ & $84(42.2)$ & $74(39.4)$ & $34(37.8)$ & 0.27 \\
\hline \multicolumn{7}{|l|}{ Income sources $^{\dagger}(n=701)$} \\
\hline Paid employment & $116(16.5)$ & $24(13.2)$ & $36(16.7)$ & $36(17.6)$ & $18(19.1)$ & 0.54 \\
\hline Recycling & $225(32.1)$ & $52(28.6)$ & $69(32.1)$ & $71(34.8)$ & $30(31.9)$ & 0.63 \\
\hline Panhandling & $243(34.7)$ & $66(36.3)$ & $87(40.5)$ & $67(32.8)$ & $21(22.3)$ & 0.02 \\
\hline Government benefits & $649(92.6)$ & $169(92.9)$ & $200(93.0)$ & $192(94.1)$ & $83(88.3)$ & 0.34 \\
\hline Friends and/or family & $341(48.6)$ & $82(45.1)$ & $120(55.8)$ & $105(51.5)$ & $31(33.0)$ & $<0.01$ \\
\hline Theft & $344(49.1)$ & $94(51.6)$ & $115(53.5)$ & $101(49.5)$ & $32(34.0)$ & 0.01 \\
\hline Selling needles & $18(2.6)$ & $4(2.2)$ & $5(2.3)$ & $7(3.4)$ & $2(2.1)$ & 0.84 \\
\hline Selling drugs & $353(50.4)$ & $95(52.2)$ & $105(48.8)$ & $115(56.4)$ & $35(37.2)$ & 0.02 \\
\hline Sex work or transactional sex & $120(17.1)$ & $36(19.8)$ & $42(19.5)$ & $27(13.2)$ & $13(13.8)$ & 0.20 \\
\hline Result of last HIV test $(n=690)$ & & & & & & $<0.01$ \\
\hline Never tested or did not receive results & $41(5.9)$ & $9(5.0)$ & $15(7.2)$ & $10(4.9)$ & $7(7.5)$ & \\
\hline Positive & $35(5.1)$ & $6(3.3)$ & $4(1.9)$ & $12(5.9)$ & $12(12.9)$ & \\
\hline Negative & $614(89.0)$ & $165(91.7)$ & 189 (90.9) & $181(89.2)$ & $74(79.6)$ & \\
\hline Ever diagnosed with Hepatitis C $(n=641)$ & $335(52.3)$ & $106(61.3)$ & $86(44.3)$ & $106(57.0)$ & $34(41.5)$ & $<0.01$ \\
\hline Currently Hepatitis C-positive ${ }^{*}(n=335)$ & & & & & & 0.56 \\
\hline Yes & $191(57.0)$ & $57(54.3)$ & $54(62.8)$ & $61(57.0)$ & $17(50.0)$ & \\
\hline No & $132(39.4)$ & $46(43.8)$ & $29(33.7)$ & $40(37.4)$ & $16(47.1)$ & \\
\hline Do not know & $12(3.6)$ & $2(1.9)$ & $3(3.5)$ & $6(5.6)$ & $1(2.9)$ & \\
\hline Drug injected most often $(n=693)$ & & & & & & $<0.01$ \\
\hline Fentanyl & $333(48.1)$ & $99(54.7)$ & $134(63.2)$ & $78(38.6)$ & $19(20.7)$ & \\
\hline Heroin & $58(8.4)$ & $16(8.8)$ & $10(4.7)$ & $21(10.4)$ & $11(12.0)$ & \\
\hline $\begin{array}{l}\text { Prescription opioids (e.g., hydromorphone, } \\
\text { morphine) }\end{array}$ & $56(8.1)$ & $15(8.3)$ & $11(5.2)$ & $25(12.4)$ & $4(4.3)$ & \\
\hline Crystal methamphetamine & $137(19.8)$ & $26(14.4)$ & $35(16.5)$ & $46(22.8)$ & $28(30.4)$ & \\
\hline Cocaine or crack/rock cocaine & $86(12.4)$ & $15(8.3)$ & $17(8.0)$ & $26(12.9)$ & $28(30.4)$ & \\
\hline
\end{tabular}


Table 3 (continued)

\begin{tabular}{|c|c|c|c|c|c|c|}
\hline \multirow[t]{2}{*}{ Characteristic } & \multirow{2}{*}{$\begin{array}{l}\text { Total } \\
n=701 n(\%)\end{array}$} & \multicolumn{4}{|c|}{$\begin{array}{l}\text { Recent frequency of SCS use (proportion of all injections at } \\
\text { SCS)* }\end{array}$} & \multirow[t]{2}{*}{$\begin{array}{l}p \\
\text { value }\end{array}$} \\
\hline & & $\begin{array}{l}\text { All or most } \\
(\geq 75 \%) \\
n=182 n(\%)\end{array}$ & $\begin{array}{l}\text { Some } \\
(26-74 \%) \\
n=215 n(\%)\end{array}$ & $\begin{array}{l}\text { Few } \\
(\leq 25 \%) \\
n=204 n(\%)\end{array}$ & $\begin{array}{l}\text { None } \\
n=94 n(\%)\end{array}$ & \\
\hline Other & $23(3.3)$ & $10(5.5)$ & $5(2.4)$ & $6(3.0)$ & $2(2.2)$ & \\
\hline $\begin{array}{l}\text { Number of years injecting (median, IQR) } \\
(n=691)\end{array}$ & $\begin{array}{l}13.0 \\
(6.0-26.0)\end{array}$ & $13.0(5.0-24.3)$ & $\begin{array}{l}11.0 \\
(5.0-18.0)\end{array}$ & $\begin{array}{l}17.0 \\
\quad(7.0-31.0)\end{array}$ & $\begin{array}{l}18.0 \\
(8.0-31.5)\end{array}$ & $<0.01$ \\
\hline Current use of opioid agonist therapy $(n=699)$ & & & & & & 0.01 \\
\hline No & $472(67.5)$ & $107(58.8)$ & $142(66.4)$ & $147(72.1)$ & $72(77.4)$ & \\
\hline Yes - methadone & $188(26.9)$ & $67(36.8)$ & $59(27.6)$ & $43(21.1)$ & $18(19.4)$ & \\
\hline Yes-buprenorphine/naloxone & $34(4.9)$ & $6(3.3)$ & $13(6.1)$ & $11(5.4)$ & $3(3.2)$ & \\
\hline Yes - other & $5(0.7)$ & $2(0.1)$ & $0(0.0)$ & $3(1.5)$ & $0(0.0)$ & \\
\hline Total & -- & $182(26.2)$ & $215(30.9)$ & $204(29.4)$ & $94(13.5)$ & -- \\
\hline
\end{tabular}

* Six participants were missing data on frequency of SCS use in the past 6 months

${ }^{\dagger}$ In the previous 6 months

\#Among those ever diagnosed

Note: proportions may not sum to $100 \%$ because of rounding

$I Q R$ interquartile range, SCS supervised consumption site

\section{Retention}

As of 23 April 2021, 291 participants (41.5\%) had completed at least one follow-up visit. Of the 410 (58.5\%) deemed lost to follow-up, 15 were known to have deceased, one was known to be incarcerated, four had moved away, and 390 were unreachable. Participants lost to survey follow-up will remain included in administrative data analysis. Baseline SCS use frequency varied by retention status. Specifically, those lost to follow-up were more likely to be non-SCS-users $(16.5 \%, n=67$ of those lost to follow-up vs. $9.3 \%, n=27$ of those retained) and less likely to use SCS for all/most injections ( $23.4 \%, n=95$ vs. $30.1 \%$, $n=87)$; these differences were statistically significant $(p=0.03)$. Participants lost to follow-up were also less likely to report income from selling drugs $(45.6 \%, n=187$ vs. $57.0 \%, n=166, p<0.01)$ at baseline. For all other variables in Table 3 , there were no significant differences between participants based on retention status (data not shown).

\section{Qualitative Studies}

In published findings from qualitative interviews with 24 clients from two SCS integrated within community health centers, participants identified benefits of the integrated SCS model including convenience and access to other health and social services [26]. Challenges of the model included limited hours of operation and building design, which were perceived as compromising participants' privacy and anonymity. Additionally, an analysis of policing in relation to SCS access found sitespecific perceptions and experiences related to differences in local drug scenes, neighborhood contexts, and police practices [27]. Interviews and observations from one site emphasized a heightened police presence in the surrounding area that led to fears of harassment and arrest whereas there was a lack of police presence at the other site, and consequently minimal fear of police encounters or potential arrest when accessing SCS.

\section{Discussion}

Longitudinal studies evaluating impacts of SCS in Canada are almost exclusively based on the Insite facility in Vancouver, Canada [6, 14]. Although the observational evaluation of Insite demonstrated numerous benefits, further research is needed to understand the impacts of diverse SCS models, in a range of geographic settings, and in the context of the current opioid overdose and emerging COVID-19 public health emergencies [14, 
Table 4 Drug-related risks among OiSIS-Toronto participants

\begin{tabular}{|c|c|}
\hline & $\begin{array}{l}\text { Total } \\
n(\%)\end{array}$ \\
\hline \multicolumn{2}{|l|}{ Frequency of injection* $(n=701)$} \\
\hline Daily & $398(56.8 \%)$ \\
\hline More than once a week & $158(22.5 \%)$ \\
\hline Once a week & $41(5.8 \%)$ \\
\hline Less than weekly & $104(14.8 \%)$ \\
\hline \multicolumn{2}{|l|}{ Injected in a public place* $(n=700)$} \\
\hline Always or most of the time & $108(15.4 \%)$ \\
\hline Some of the time or occasionally & $462(66.0 \%)$ \\
\hline Never & $130(18.6 \%)$ \\
\hline \multicolumn{2}{|l|}{ Injected alone* $(n=697)$} \\
\hline Always or most of the time & $183(26.3 \%)$ \\
\hline Some of the time or occasionally & $431(61.8 \%)$ \\
\hline Never & $83(11.9 \%)$ \\
\hline \multicolumn{2}{|l|}{ Needed help to inject* $(n=701)$} \\
\hline Always or most of the time & $73(10.4 \%)$ \\
\hline Some of the time or occasionally & $216(30.9 \%)$ \\
\hline Never & $411(58.7 \%)$ \\
\hline Borrowed a used syringe* $(n=698)$ & $104(14.9 \%)$ \\
\hline Lent a used syringe* $(n=701)$ & $120(17.1 \%)$ \\
\hline $\begin{array}{l}\text { Receptively shared other } \\
\text { injecting equipment* } \\
(n=699)\end{array}$ & $260(37.2 \%)$ \\
\hline $\begin{array}{l}\text { Filled syringe from a syringe used by } \\
\text { someone else* } \\
(n=696) \\
\text { Smoked crack cocaine* }(n=562)\end{array}$ & $141(20.3 \%)$ \\
\hline Daily or more than once a week & $205(36.5 \%)$ \\
\hline Weekly to monthly & $99(17.6 \%)$ \\
\hline Less than monthly & $53(9.4 \%)$ \\
\hline Never & $205(36.5 \%)$ \\
\hline \multicolumn{2}{|c|}{ Smoked crystal methamphetamine* $(n=565)$} \\
\hline Daily or more than once a week & $113(20.0 \%)$ \\
\hline Weekly to monthly & $102(18.1 \%)$ \\
\hline Less than monthly & $51(9.0 \%)$ \\
\hline Never & $299(52.9 \%)$ \\
\hline \multicolumn{2}{|l|}{$\begin{array}{l}\text { Heavy alcohol use } \\
\qquad(\geq 6 \text { drinks in one sitting })^{*}(n=698)\end{array}$} \\
\hline Daily or more than once a week & $111(15.9 \%)$ \\
\hline Weekly to monthly & $86(12.3 \%)$ \\
\hline Less than monthly & $104(14.9 \%)$ \\
\hline Never & $397(56.9 \%)$ \\
\hline Ever overdosed $(n=699)$ & $489(70.0 \%)$ \\
\hline Recent overdose* $(n=699)$ & $270(38.6 \%)$ \\
\hline
\end{tabular}

*Over the previous 6 months
16]. To address these gaps, the OiSIS-Toronto cohort has recruited 701 PWID and will follow their health and social outcomes using a combination of self-report and administrative data. As indicated by the baseline data presented herein, and consistent with previous studies of SCS clients, [29] the study population experiences multiple forms of social and structural vulnerability: over 9 in 10 were homeless or unstably housed and over onethird were recently incarcerated. Almost half are of Indigenous ancestry and/or belong to racialized groups that, as a consequence of structural racism, often experience poorer health in Canada [30]. About half of participants reported that fentanyl was their most commonly used drug and consequently the study population is at high risk of overdose. Over a third reported having overdosed in the previous 6 months. This is comparable to the estimated lifetime prevalence of overdose among PWID globally, [31] attesting to the greater risk presented by unpredictable concentrations of fentanyl and other potent synthetic opioids present in Toronto's street drug supply [20]. Current OAT enrollment (32.5\%) was low, indicating an unmet need for patient-centered treatment in this population at high overdose risk.

Future analyses using the OiSIS-Toronto data will assess how SCS use, including use of various SCS models, relates to self-reported behaviors as well as OAT and other healthcare use ascertained through health administrative data linkages. A notable strength of the cohort is the use of administrative data to objectively ascertain utilization of publicly insured primary and hospital care, as well as OAT dispensation. Few previous SCS evaluations have included healthcare data linkages, and only to a single local hospital [32] or to local detoxification facilities [33]. It is notable that the vast majority of participants $(90.2 \%)$ consented to administrative data linkages (for which no additional incentive was provided), of whom most (82.4\%) were successfully linked, despite the majority of consenting participants having not provided complete information. Furthermore, access to the SCS visit database to validate self-reported frequency of SCS use will facilitate the application of bias-adjustment methods.

An additional strength of the cohort lies in the opportunity to evaluate the uptake and effectiveness of emergent harm reduction interventions using quantitative, qualitative, and mixed methods, including legally sanctioned drug checking services and safer opioid supply programs. 
These programs are being implemented by the CHAs where our study SCS are located, allowing for a rapid research response, including embedding survey questions on service preferences, facilitators and barriers to uptake, and client experiences.

Recruiting and retaining socially and structurally vulnerable PWID in longitudinal research are challenging, [21, 34, 35] and OiSIS-Toronto has faced limitations in this regard, even prior to the COVID-19 pandemic. First, recruitment of PWID who do not use SCS was slower than anticipated despite employing multiple means of outreach and referral. This may reflect that a high proportion of PWID in Toronto has already been exposed to SCS, as well as the lack of a dense geographic concentration of PWID. This is compounded by resource limitations precluding the placement of study outreach workers at multiple locations. In contrast, most Canadian longitudinal research with PWID comes from Vancouver, Canada, where PWID, SCS, and cohort study offices are concentrated in one compact area and PWID are highly familiar with longitudinal cohort studies [36].

Similar factors may have impacted study retention. Due to high rates of homelessness, incarceration, and mortality, loss to follow-up is typically high in PWID cohorts, ranging from 20 to $50 \%$ per year $[21,35,37$, 38 ]. Our loss to follow-up is $58.5 \%$, primarily because of the inability to reach participants through any of the means of contact they provided. Considering the high unconfirmed mortality rate of $2.1 \%$, based on word of mouth alone, it is likely that our administrative data linkage will reveal that a higher proportion of loss to follow-up was related to participant death. Incarceration cannot be ascertained through currently available data linkages but likely contributes significantly to the inability to reach participants. In addition to the aforementioned factors impacting retention, the COVID-19 pandemic has substantially impacted our capacity to recruit and retain participants, and this impact is ongoing. Innovative retention strategies increasingly used in cohort studies, such as use of social media to keep in touch with participants and reminders from CHA staff and clinicians, [41-41] have been considered by the research team to enhance retention. However, we encountered challenges in engaging with a research ethics board with experience in in-hospital clinical studies and continue to work to adapt ethics processes to community-based research designs.

Although there were few observed differences between participants lost to follow-up and those retained for at least one visit, retention of participants who did not use SCS was poorer due to limited opportunities for opportunistic engagement with field study staff. Ongoing efforts will focus on recruitment and retention of non-SCS-users in close geographic proximity to SCS sites. We note that the inclusion of non-SCS comparison groups presents challenges across studies due to issues of confounding by indication [12, 28]. Future research in other settings should consider prospectively recruiting PWID prior to SCS implementation; this was the original intended design of OiSIS-Toronto but was not possible due to the timing of study funding and earlierthan-expected opening of SCS.

Finally, non-random sampling is an important limitation to generalizability of our study but typical of PWID cohorts. Random selection of SCS clients was not possible due to the operational features of the study sites (e.g., allowing for anonymity); however, we recruited a large fraction of SCS clients (the three CHAs had an estimated total of 989 active unique clients over the quarter preceding March 2020).

\section{Conclusions}

With a focus on evaluating the secondary impacts of SCS on healthcare use and identifying how service integration and other operational characteristics impact client outcomes, the OiSIS-Toronto cohort responds to the need for a "second generation" of SCS research that examines how heterogeneous models and client populations impact SCS effectiveness [16]. The cohort further provides the opportunity to evaluate a number of emergent interventions being delivered within Toronto's network of harm reduction services as well as the impact of COVID-19 on the health, social wellbeing, and clinical trajectories of PWID. Ultimately, administrative data linkages with very high opt-in will enable retrospective and prospective studies of the impact of access to integrated SCS models on healthcare and OAT outcomes. 
Acknowledgements We wish to thank our research participants for their invaluable contributions to the study. We thank Sufiat Fusigboye for assistance with manuscript preparation. The Ontario Integrated Supervised Injection Services Research Program team includes Sean B. Rourke, Stefan Baral, Gary Garber, Lynne Leonard, Ayden Scheim, Thomas Kerr, Dan Werb, Elizabeth McLean, Jean Bacon, Geoff Bardwell, Tara Gomes, Mary-Clare Kennedy, Zack Marshall, Margaret Millson, Sanjana Mitra, Beth Rachlis, Carol Strike, and Kednapa Thavorn. We would also like to thank Josie Chundamala for research and administrative support. We acknowledge the land on which we conducted our research is the traditional territory of many nations including the Mississaugas of the Credit, the Anishnabeg, the Chippewa, the Haudenosaunee, and the Wendat Peoples, and home to many diverse First Nations, Inuit, and Métis Peoples.

Funding OiSIS-Toronto is funded by the Canadian Institutes of Health Research (CIHR; PJT - 153152). The study also receives support from the St. Michael's Hospital Foundation. Qualitative studies were funded via a CIHR Foundation Grant (20R74326). AIS and GB were supported by CIHR Fellowships. DW is supported by a CIHR New Investigator Award, an Early Researcher Award from the Ontario Ministry of Research, Innovation and Science, and the St. Michael's Hospital Foundation.

Open Access This article is licensed under a Creative Commons Attribution 4.0 International License, which permits use, sharing, adaptation, distribution and reproduction in any medium or format, as long as you give appropriate credit to the original author(s) and the source, provide a link to the Creative Commons licence, and indicate if changes were made. The images or other third party material in this article are included in the article's Creative Commons licence, unless indicated otherwise in a credit line to the material. If material is not included in the article's Creative Commons licence and your intended use is not permitted by statutory regulation or exceeds the permitted use, you will need to obtain permission directly from the copyright holder. To view a copy of this licence, visit http://creativecommons.org/licenses/by/4.0/.

\section{References}

1. Jacka B, Larney S, Degenhardt L, Janjua N, Høj S, Krajden $\mathrm{M}$, et al. Prevalence of injecting drug use and coverage of interventions to prevent HIV and Hepatitis C Virus infection among people who inject drugs in Canada. Am J Public Health. 2020;110(1):45-50. https://doi.org/10.2105 /AJPH.2019.305379.

2. Special Advisory Committee on the Epidemic of Opioid Overdoses. Opioid and stimulant-related harms in Canada. Ottawa: Public Health Agency of Canada; March 202. Accessed 23 April 2021. https://health-infobase.canada. ca/substance-related-harms/opioids-stimulants/

3. Interactive Opioid Tool. Public Health Ontario. Accessed March 5, 2020. https://www.publichealthontario.ca/Data and Analysis/Substance Use/Interactive Opioid Tool

4. Kerr T, Mitra S, Kennedy MC, McNeil R. Supervised injection facilities in Canada: past, present, and future. Harm
Reduct J. 2017;14(1):28. https://doi.org/10.1186/s12954017-0154-1.

5. Supervised Consumption Services | Drug Policy Alliance. Published March 5, 2020. Accessed March 5, 2020. http://www.drugpolicy.org/issues/supervised-consumptionservices

6. Kennedy MC, Karamouzian M, Kerr T. Public health and public order outcomes associated with supervised drug consumption facilities: a systematic review. Curr HIV/AIDS Rep. 2017;14(5):161-83. https://doi.org/10.1007/s11904017-0363-y.

7. Marshall BD, Milloy M-J, Wood E, Montaner JS, Kerr T. Reduction in overdose mortality after the opening of North America's first medically supervised safer injecting facility: a retrospective population-based study. Lancet. 2011;377(9775):1429-37. https://doi.org/10.1016/S01406736(10)62353-7.

8. DeBeck K, Kerr T, Bird L, Zhang R, Marsh D, Tyndall M, et al. Injection drug use cessation and use of North America's first medically supervised safer injecting facility. Drug Alcohol Depend. 2011;113(2-3):172-6. https://doi. org/10.1016/j.drugalcdep.2010.07.023.

9. Kerr T, Tyndall M, Li K, Montaner J, Wood E. Safer injection facility use and syringe sharing in injection drug users. Lancet. 2005;366(9482):316-8. https://doi. org/10.1016/S0140-6736(05)66475-6.

10. Stoltz J-A, Wood E, Small W, Li K, Tyndall M, Montaner J, et al. Changes in injecting practices associated with the use of a medically supervised safer injection facility. J Public Health. 2007;29(1):35-9. https://doi.org/10.1093 /pubmed/fd1090.

11. Wood E, Kerr T, Small W, Li K, Marsh DC, Montaner JS, et al. Changes in public order after the opening of a medically supervised safer injecting facility for illicit injection drug users. Can Med Assoc J. 2004;171(7):731-4. https://doi.org/10.1503/cmaj.1040774.

12. Kennedy MC, Hayashi K, Milloy M-J, Wood E, Kerr T. Supervised injection facility use and all-cause mortality among people who inject drugs in Vancouver, Canada: a cohort study. PLoS Med. 2019;16(11):e1002964. https://doi. org/10.1371/journal.pmed.1002964.

13. Potier C, Laprévote V, Dubois-Arber F, Cottencin O, Rolland B. Supervised injection services: what has been demonstrated? A systematic literature review. Drug Alcohol Depend. 2014;145:48-68. https://doi.org/10.1016 /j.drugalcdep.2014.10.012.

14. Belackova V, Salmon AM, Day CA, Ritter A, Shanahan M, Hedrich D, et al. Drug consumption rooms: a systematic review of evaluation methodologies. Drug Alcohol Rev. 2019;38(4):406-22. https://doi.org/10.1111/dar.12919.

15. Caulkins JP, Pardo B, Kilmer B. Supervised consumption sites: a nuanced assessment of the causal evidence. Addiction. 2019;114(12):2109-15. https://doi.org/10.1111 /add.14747.

16. Scheim A, Werb D. Integrating supervised consumption into a continuum of care for people who use drugs. Can Med Assoc J. 2018;190(31):E921-2. https://doi.org/10.1503 /cmaj.180824.

17. Foreman-Mackey A, Bayoumi AM, Miskovic M, Kolla G, Strike C. 'It's our safe sanctuary': experiences of using an unsanctioned overdose prevention site in Toronto. Ontario 
Int J Drug Policy. 2019;73:135-40. https://doi.org/10.1016 /j.drugpo.2019.09.019.

18. Maghsoudi N, McDonald K, Stefan C, et al. Evaluating networked drug checking services in Toronto, Ontario: study protocol and rationale. Harm Reduct J. 2020;17(1):9. https://doi.org/10.1186/s12954-019-0336-0.

19. Ivsins A, Boyd J, Beletsky L, McNeil R. Tackling the overdose crisis: the role of safe supply. Int $J$ Drug Policy. 2020;80:102769. https://doi.org/10.1016/j. drugpo.2020.102769.

20. Centre on Drug Policy Evaluation. Toronto's Drug Checking Service. Accessed December 2, 2020. https://drugchecking.cdpe.org/

21. Horyniak D, Higgs P, Jenkinson R, Degenhardt L, Stoové M, Kerr T, et al. Establishing the Melbourne injecting drug user cohort study (MIX): rationale, methods, and baseline and twelve-month follow-up results. Harm Reduct J. 2013;10(1):11. https://doi.org/10.1186/1477-7517-10-11.

22. Tyndall MW, Currie S, Spittal P, Li K, Wood E, O'Shaughnessy MV, et al. Intensive injection cocaine use as the primary risk factor in the Vancouver HIV-1 epidemic. AIDS. 2003;17(6):887-93. https://doi.org/10.1097 /00002030-200304110-00014.

23. Bush K. The AUDIT Alcohol Consumption Questions (AUDIT-C): an effective brief screening test for problem drinking. Arch Intern Med. 1998;158(16):1789-95. https://doi.org/10.1001/archinte.158.16.1789.

24. Kroenke K, Spitzer RL, Williams JB. The PHQ-9: validity of a brief depression severity measure. J Gen Intern Med. 2001;16(9):606-13. https://doi.org/10.1046/j.15251497.2001.016009606.x.

25. Welcome to neo360. Accessed March 5, 2020. http://www. neo360.co/

26. Bardwell G, Strike C, Mitra S, Scheim A, Barnaby L, Altenberg J, et al. That's a double-edged sword: exploring the integration of supervised consumption services within community health centres in Toronto, Canada. Health Place. 2020;61:102245. https://doi.org/10.1016/j. healthplace.2019.102245.

27. Bardwell G, Strike C, Altenberg J, Barnaby L, Kerr T. Implementation contexts and the impact of policing on access to supervised consumption services in Toronto, Canada: a qualitative comparative analysis. Harm Reduct J. 2019;16(1): 30. https://doi.org/10.1186/s12954-019-0302-x.

28. Scheim AI, Bouck Z, Tookey P, Hopkins S, Sniderman R, McLean E, et al. Supervised consumption service use and recent non-fatal overdose among people who inject drugs in Toronto, Canada. Int J Drug Policy. 2021;87:102993. https://doi.org/10.1016/j.drugpo.2020.102993.

29. Wood E, Tyndall MW, Li K, Lloyd-Smith E, Small W, Montaner JSG, et al. Do Supervised injecting facilities attract higher-risk injection drug users? Am J Prev Med. 2005;29(2):126-30. https://doi.org/10.1016/j. amepre.2005.04.011.

30. Allan B, Smylie J. First peoples, second class treatment: the role of racism in the health and well-being of Indigenous Peoples in Canada. Toronto (ON): Wellesley Institute; 2015.

31. Colledge S, Peacock A, Leung J, Larney S, Grebely J, Hickman M, et al. The prevalence of non-fatal overdose among people who inject drugs: a multi-stage systematic review and meta-analysis. Int J Drug Policy. 2019;73:17284. https://doi.org/10.1016/j.drugpo.2019.07.030.

32. Lloyd-Smith E, Wood E, Zhang R, Tyndall MW, Sheps S, Montaner JSG, et al. Determinants of hospitalization for a cutaneous injection-related infection among injection drug users: a cohort study. BMC Public Health. 2010;10:327. https://doi.org/10.1186/1471-2458-10-327.

33. Wood E, Tyndall MW, Zhang R, Stoltz JA, Lai C, Montaner JSG, et al. Attendance at supervised injecting facilities and use of detoxification services. $N$ Engl J Med. 2006;354(23): 2512-4. https://doi.org/10.1056/NEJMc052939.

34. Scott CK. A replicable model for achieving over $90 \%$ follow-up rates in longitudinal studies of substance abusers. Drug Alcohol Depend. 2004;74(1):21-36. https://doi. org/10.1016/j.drugalcdep.2003.11.007.

35. Garfein RS, Swartzendruber A, Ouellet LJ, Kapadia F, Hudson SM, Thiede $\mathrm{H}$, et al. Methods to recruit and retain a cohort of young-adult injection drug users for the Third Collaborative Injection Drug Users Study/Drug Users Intervention Trial (CIDUS III/DUIT). Drug Alcohol Depend. 2007;91:S4-S17. https://doi.org/10.1016/j. drugalcdep.2007.05.007.

36. Wood E, Kerr T, Lloyd-Smith E, Buchner C, Marsh DC, Montaner JSG, et al. Methodology for evaluating Insite: Canada's first medically supervised safer injection facility for injection drug users. Harm Reduct J. 2004;1(1):9. https://doi.org/10.1186/1477-7517-1-9.

37. Sordo L, Bravo MJ, Barrio G, Indave BI, Degenhardt L, Pastor-Barriuso R. Potential bias due to outcome-related loss to follow-up in cohort studies on incidence of drug injection: systematic review and meta-analysis. Addiction. 2015;110(8):1247-57. https://doi.org/10.1111/add.12940.

38. Galai N, Safaeian M, Vlahov D, Bolotin A, Celentano DD. Longitudinal patterns of drug injection behavior in the ALIVE Study Cohort,1988-2000: description and determinants. Am J Epidemiol. 2003;158(7):695-704. https://doi. org/10.1093/aje/kwg209.

39. Teague S, Youssef GJ, Macdonald JA, et al. Retention strategies in longitudinal cohort studies: a systematic review and meta-analysis. BMC Med Res Methodol. 2018;18(1): 151. .https://doi.org/10.1186/s12874-018-0586-7

40. Kirwan A, Curtis M, Dietze P, Aitken C, Woods E, Walker $\mathrm{S}$, et al. The Prison and Transition Health (PATH) Cohort Study: study protocol and baseline characteristics of a cohort of men with a history of injecting drug use leaving prison in Australia. J Urban Health. 2019;96(3):400-10. https://doi. org/10.1007/s11524-019-00353-5.

41. Stephenson NL, Hetherington E, Dodd S, Mathews A, Tough S. Mitigation of participant loss to follow-up using Facebook: All Our Families Longitudinal Pregnancy Cohort. J Med Internet Res. 2019;21(2): 10441. https://doi.org/10.2196/10441.

Publisher's Note Springer Nature remains neutral with regard to jurisdictional claims in published maps and institutional affiliations. 